\title{
Editorial
}

\section{Are we really ready to implement large-scale storage?}

Andy Chadwick, British Geological Survey

As COP 21 approaches and with CCS perhaps gaining a new momentum, a question often posed is: are we really ready to implement large-scale storage? In other words do we have sufficient hands-on experience from current storage projects, together with theoretical understanding of subsurface processes, to confidently proceed with full industrial-scale storage rollout?

So what is the state of play? Over the past twenty years or so three medium-scale storage projects (injecting around one million tonnes ( $\mathrm{Mt}$ ) of $\mathrm{CO}_{2}$ per year) and number of much smaller pilot injection tests have been developed across the world. The latter have helped to confirm and refine detailed understanding of subsurface fluid interactions and our ability to monitor these, but it is the operations at Sleipner, Snøhvit and In Salah that provide the key pointers to what lies ahead. These projects have together injected over $20 \mathrm{Mt}$ of $\mathrm{CO}_{2}$ and, in many respects, have performed according to expectation. So for Sleipner, injecting into a very large, thick, homogeneous reservoir, wide lateral plume spread and low storage efficiency are the key issues. Snøhvit and In Salah, injecting into thinner, deeper, reservoirs, with more structural and stratigraphical complexity, both encountered significant pressure issues which required remedial action; at Snøhvit injection continues into an alternative storage reservoir and at In Salah injection has now ceased. So, by 'according to expectation' I refer to Table 3.1 in the CO2STORE Best Practice Manual ${ }^{1}$ which, in summarising key positive and negative reservoir attributes, predicts that reservoirs with characteristics similar to those at In Salah and Snøhvit would indeed prove problematical for large-scale storage.

Four new medium-scale full-chain storage projects are currently at the planning/implementation stage. The Quest (Canada) and White Rose (UK) projects aim to inject into saline aquifers and the ROAD (Netherlands) and Goldeneye (UK) projects plan to utilise depleted gas fields. Depleted fields are the low-hanging fruit for early storage rollout because their dynamic fluid behaviour is already well understood and the pressure-sink effect will minimise containment risk. But scale-up is the issue and saline aquifers represent the major storage resource worldwide. The Gorgon project in Australia has a key role to play here. Planning to inject around $100 \mathrm{Mt}$ of $\mathrm{CO}_{2}$ at a rate of 3-4 Mt per year, storage will be in a deep saline aquifer and pressure control is planned via a number of water production wells. In this respect it sits between the current medium-scale projects and future largescale ones. It must also be added that the vast proportion of anthropogenic $\mathrm{CO}_{2}$ currently stored underground is via $\mathrm{CO}_{2}$ enhanced oil recovery, such as at Weyburn-Midale and the recently commenced Boundary Dam projects. These North American operations have stored in the region of $30 \mathrm{Mt}$ of anthropogenic $\mathrm{CO}_{2}$, so far without incident, and other projects are in the pipeline. Again, extensive research activity is providing more invaluable information on storage processes and monitoring tool development.

So, my answer to the initial question is 'yes' but with qualifications. We need to learn by doing and we need to accept that storage sites will never perform exactly as predicted. Crucially we need to avoid surprises and unexpected outcomes as storage rolls out. These will damage storage credibility 
in the eyes of regulators and the public. So, it is vital not to focus eagerly on the 'median' or preferred predictive scenarios for site performance, but rather to pay heed to the less likely, more extreme scenarios and their outcomes (the 'known unknowns') and ensure that, by means of suitable monitoring and remediation planning, we can manage these. A step-by-step approach, learning by experience, heeding uncertainty and maintaining robust monitoring and remediation protocols at all times, is the key to successful large-scale storage rollout.

${ }^{1}$ Chadwick, R.A., Arts, R., Bernstone, C., May, F., Thibeau, S \& Zweigel, P. 2008. Best Practice for the Storage of $\mathrm{CO}_{2}$ in Saline Aquifers. Keyworth, Nottingham: British Geological Survey Occasional Publication No. 14. ISBN: 978-0-85272-610-5. 277 pp.

${ }^{2}$ Chadwick, R.A. \& Noy, D.J. 2015 Underground $\mathrm{CO}_{2}$ storage: demonstrating regulatory conformance by convergence of history-matched modelled and observed $\mathrm{CO}_{2}$ plume behaviour using Sleipner time-lapse seismics. Greenhouse Gases: Science \& Technology, 5: 305-322. DOI: 10.1002/ghg.

Published online at Wiley Online Library. DOI: 10.1002/ghg.1560 